\title{
Ergonomics
}

\section{Moisture vapour permeable gloves extend thermal endurance and safe work time more than other similarly permeable chemical-biological ancillary protective items.}

\section{Christie N Godsmark, Michael J Tipton, Michael R Dennis \& James R House}

To cite this article: Christie N Godsmark, Michael J Tipton, Michael R Dennis \& James R House (2018): Moisture vapour permeable gloves extend thermal endurance and safe work time more than other similarly permeable chemical-biological ancillary protective items., Ergonomics, DOI: 10.1080/00140139.2018.1503726

To link to this article: https://doi.org/10.1080/00140139.2018.1503726 Jul 2018.

Submit your article to this journal $\widetilde{ }$

山ll Article views: 14

View Crossmark data [ 
Moisture vapour permeable gloves extend thermal endurance and safe work time more than other similarly permeable chemical-biological ancillary protective items.

\section{Christie N Godsmark ${ }^{1}$, Michael J Tipton ${ }^{1}$, Michael R Dennis ${ }^{2}$, James R} House $^{1 *}$

${ }^{1}$ Extreme Environments Laboratory, Department of Sport and Exercise Science, University of Portsmouth, Portsmouth, United Kingdom

${ }^{2}$ Defence Science and Technology Laboratory, Porton Down, Salisbury, United Kingdom

*Corresponding Author: James R House (jim.house@ port.ac.uk) +44 (0)239284 5594

Department of Sport and Exercise Science, Spinnaker Building, Cambridge Road, Portsmouth, PO1 2ER, United Kingdom.

Acknowledgements: This work was supported by the University of Portsmouth, UK and we would like to thank the Defence Science and Technology Laboratory for the gift of equipment. We would like to acknowledge the participants and the assistance of Mr Danny White, Mr Geoff Long, Dr Ella Walker, Miss Jennifer Dyer, Mrs Nicola Armstrong and Mr Nicolas Desnos.

Word Count: 5852 


\title{
Moisture vapour permeable gloves extend thermal endurance and safe work time more than other similarly permeable chemical-biological ancillary protective items.
}

\begin{abstract}
Working in chemical biological (CB) protective equipment causes thermoregulatory strain by restricting evaporative cooling. We quantified which impermeable ancillary items [gloves(G), body armour liner(BAL), respirator(R), overboots(OB)] imposed the greatest and least thermoregulatory strain through restricting evaporative cooling. The study was a five-condition repeatedmeasures design with male volunteers $(n=13)$ who stepped intermittently with recovery periods in a desert-like environment $\left(40.5^{\circ} \mathrm{C}, 20 \% \mathrm{rh}\right)$. Conditions varied in the ensemble worn, with a matched weight secured to the area when an item was not worn: CON(CB suit plus all items), $\mathrm{N}_{\mathrm{R}}$ (no R), $\mathrm{N}_{\mathrm{BAL}}$ (no BAL [170g liner]), $\mathrm{N}_{\mathrm{G}}$ (no $\left.\mathrm{G}\right), \mathrm{N}_{\mathrm{OB}}$ (no $\mathrm{OB}$ ). The greatest reduction in thermoregulatory strain compared to $\mathrm{CON}$ occurred in $\mathrm{N}_{\mathrm{G}}$ when the rise of rectal temperature was attenuated by $0.37^{\circ} \mathrm{C} . \mathrm{hr}^{-1}(\mathrm{p}<0.001)$, extending tolerance time by $21.3 \%(\mathrm{p}<0.05)$ and improving perceived thermal comfort. The least improvement occurred for $\mathrm{N}_{\mathrm{OB}}$. It is recommended that the $\mathrm{G}$ permeability be examined further.
\end{abstract}

Keywords: thermoregulation; permeability; gloves; CBRN; heat strain

Practitioner Summary: Thermoregulatory strain was quantified when wearing impermeable protective equipment. The thermal burden of intermittent exercise in desert-like environments was best alleviated by removing gloves compared to removing a respirator, overboots or body armour liner. Reducing the evaporative resistance of materials used for such kit, particularly gloves, should be investigated.

\section{Introduction}

Many occupations, both civilian and military, require personnel to wear protective clothing. On some occasions such as in Fire and Rescue Services, Chemical and Energy Industries and the military this protective clothing, whilst alleviating one form of risk, can introduce another in the form of heat illness due to the impairment in thermoregulatory capacity imposed by the protective clothing. The warfighter working 
whilst wearing chemical and biological (CB) personal protective equipment (PPE) is at risk of developing heat illness due to the moisture-vapour restrictive and insulative properties of the clothing and equipment. The typical ensemble comprises of a hooded jacket and trouser made from air permeable materials, thus allowing some moisture vapour (evaporated sweat) to pass through the clothing to the environment thereby gradually contributing to evaporative cooling. Additionally, various ancillary CB moisture-vapour impermeable (MVIP) items are worn. These MVIP ancillary items: a respirator $(\mathrm{R})$, gloves $(\mathrm{G})$ and overboots $(\mathrm{OB})$ block the transfer of moisture vapour to the environment and thus prevent evaporative cooling once the underlying microclimate becomes saturated. Body armour (BA) is also worn in most military operations and is usually made from materials that are either primarily, or partly, MVIP. If metabolic heat production and any environmental heat gain exceeds thermophysiological heat loss mechanisms, for example when exercising in PPE, uncompensable heat strain can develop (Lind 1963; Montain et al. 1994). This results in a continued rise of body temperature, which if unchecked by a reduction in metabolic heat production or the implementation of cooling strategies, will culminate in heat illness that can be fatal. Improving the moisture vapour permeability (MVP) of ancillary CB items and BA, particularly in a hot, dry desert environment that fosters a favourable vapour pressure gradient with saturated skin, would allow for a greater transfer of moisture vapour through the PPE. This would enhance evaporative cooling, reducing whole body thermoregulatory strain and extend endurance time. The aim of this study was to quantify the thermoregulatory impact of each ancillary item to determine the potential advantage of making future items from MVP materials.

The ancillary items: $\mathrm{R}, \mathrm{G}$ and $\mathrm{OB}$ cover the face, hands and combat boots respectively with BA covering the suit over the torso. Therefore, when investigating 
which of these items impose the greatest or the least thermoregulatory strain on the wearer, regional characteristics favouring heat loss such as surface area available for moisture vapour exchange, sweat rate and cutaneous blood flow will determine the degree of reduction to whole body thermoregulatory strain. The approximate percentage of total body surface area of each region is $2.7 \%$ for the face (manikin Newton, Thermetrics, US), $4.6 \%$ for both hands (Yu, Hsu, and Chen 2008), $8.1 \%$ for both feet (Yu and Tu 2009), whilst bearing in mind that the feet are enclosed in largely MVIP combat boots, and $39.5 \%$ for the torso (Weiner 1945), again noting that the CB suit covers majority of the body including the entire torso area. The rate of sweat production for minimally clothed males undertaking moderate exercise (treadmill running at $55 \%$ of $\dot{\mathrm{V}} \mathrm{O}_{2 \max }$ ) in warm conditions is greatest at the back (approximately $771 \mathrm{~g} \cdot \mathrm{m}^{-2} \cdot \mathrm{hr}^{-1}$ ) and forehead (approximately $697 \mathrm{~g} \cdot \mathrm{m}^{-2} \cdot \mathrm{hr}^{-1}$ ) with lower rates found at the dorsal hand (approximately $126 \mathrm{~g} \cdot \mathrm{m}^{-2} \cdot \mathrm{hr}^{-1}$ ) and foot (approximately $202 \mathrm{~g} \cdot \mathrm{m}^{-2} \cdot \mathrm{hr}^{-1}$ ), and the cheek displaying the lowest rate overall (approximately $85 \mathrm{~g} \cdot \mathrm{m}^{-2} \cdot \mathrm{hr}^{-1}$ ) (Smith and Havenith 2011). Regional variations in cutaneous blood flow have not been extensively cited in the literature for all the areas of interest in this study however, the hands and feet in particular support a large blood flow made possible by the high densities of capillaries (Grant and Bland 1931) and cutaneous arteriovenous anastomoses (Hales 1985).

Regional thermoreception might also affect whole body thermoregulatory strain, particularly as thermal comfort is known to drive thermoregulatory behaviour (Weiss and Laties 1961; Frank et al. 1999). The density and sensitivity of thermoreceptors are not homogenously distributed throughout the skin (Nadel, Mitchell, and Stolwijk 1973; Cotter et al. 1996; Cotter and Taylor 2005) and many cooling strategies for heat stressed individuals target the highly sensitive face (Mündel et al. 2006). Penfield and Boldrey (1937) when developing the somatosensory homunculus which, although not exclusive 
to temperature sensation alone, highlighted that, along with the face, the hands provide large sensory feedback to the brain in comparison to the trunk for example. Fukazawa and Havenith (2009) found that the periphery (arms and thighs) also possesses a higher sensitivity of thermal discomfort to skin wettedness compared to the torso. The current study is concerned with regional thermal perturbations on the whole body response and Zhang (2003) found that in a warm environment, overall thermal comfort tends to follow the local thermal comfort of the head and face.

The general aim of this study was to independently quantify the reduction to thermoregulatory strain (physiological and perceptual) when each MVIP ancillary item $(\mathrm{R}, \mathrm{G}, \mathrm{OB}$ and $\mathrm{BAL})$ was not worn during exercise and recovery in a desert-like environment. To eliminate the influence of removing varying weights between conditions on metabolic heat production, when an item was not worn a weight matching the mass of the item was secured to the area from where the item had been removed as a surrogate for making the item completely MVP. We hypothesized that the largest reduction to thermoregulatory strain would be evident when $G$ were not worn, with the OB the least; while the largest reduction to perceived thermoregulatory strain being evident when the $\mathrm{R}$ was not worn.

\section{Methods}

\section{Experimental Design}

The study protocol was given a favourable opinion by the University of Portsmouth Scientific Faculty Ethics Committee, alongside approval from The Ministry of Defence Research Ethics Committee for the use of equipment. All procedures are compliant with the Declaration of Helsinki. Thirteen volunteer male participants (mean [SD] age: 21.5 [2.4] years, height: 178.3 [5.0] cm, weight: 75.7 [9.7] kg, body fat: 14.4 [4.1] \%) were 
recruited from the University of Portsmouth student cohort and gave informed consent. The study was a counter-balanced five-condition repeated measures design in which each participant undertook intermittent work-recovery periods in an environmental chamber for up to 170 minutes (Figure 1).

Figure 1. The work and recovery experimental design to allow for calculations of rates of heating and cooling as well as to optimize the detection of differences between conditions. Note that grey shaded areas represent exercise.

The study conditions were varied by the combinations of ancillary items that were worn. In the control $(\mathrm{CON})$ condition all items were worn $(\mathrm{CB}$ suit $+\mathrm{R}+\mathrm{BAL}+$ $\mathrm{G}+\mathrm{OB})$. Subsequent conditions involved the removal of one item whilst all other items were worn $\left(\mathrm{N}_{\mathrm{R}}\right.$ : No R thereby exposing the face; $\mathrm{N}_{\mathrm{BAL}}$ : No BAL thereby uncovering the torso section of the suit; $\mathrm{N}_{\mathrm{G}}$ : No $\mathrm{G}$ thereby exposing the hands; $\mathrm{N}_{\mathrm{OB}}$ : No OB thereby exposing the combat boots). To quantify the thermal burden imposed by each item independently of the mass, when an item was not worn for a condition a weight equivalent to the mass of the item was attached to the body site from where the item had been removed. For example, when $\mathrm{G}$ were not worn, weights with an equivalent mass (120 g, Table I) were attached to each wrist. Thus, any reductions to whole body thermoregulatory strain could be attributed to the improved MVP at the area of interest rather than a reduced overall metabolic heat production. Furthermore, when quantifying the thermal burden of BA, a weight of $180 \mathrm{~g}$ that represented the mass of the impermeable liner reflecting the impermeability and shape of BA was secured to the torso rather than attempting to secure $15 \mathrm{~kg}$ (approximate weight of actual BA) to the torso.

The characteristics of the PPE worn during the experiment are shown in Table I, and give, for the particular size shown, a total mass of PPE worn + participants own 
underwear and socks. The mass of each item varied with size, so the information below relate to the sizes reported below.

Table I. Clothing and personal protective equipment characteristics.

\section{Experimental Protocol}

\section{Environmental Chamber Preparation}

Environmental conditions were controlled at $40.5{ }^{\circ} \mathrm{C}$ air temperature and $20 \%$ rh in an environmental chamber. These values represent the mean conditions between 08:00 and 21:00 for countries in a hot and dry category of the UK Ministry of Defence Standard produced by the Meteorological Office (2000). The environmental conditions were constantly recorded using a wet-bulb globe thermometer (Edale Instruments Ltd, UK) and electronically logged every minute (Squirrel 1000, Grant Instruments [UK] Ltd, UK).

\section{Participant Preparation and Instrumentation}

All experiments took place in the morning, between 08:00 and 13:00 to eliminate any influence of the circadian rhythm on thermoregulation (Kräuchi and Wirz-Justice 1994). On each test day, participants were instructed to eat a light breakfast and arrive at the laboratory in a euhydrated state. Participants were asked to refrain from alcohol the day prior to testing, and caffeine for two hours prior to testing. Participants were weighed naked (Model I10, Ohaus Corporation, US) and then self-inserted a rectal thermistor (Edale Instruments Ltd, UK) to $15 \mathrm{~cm}$ beyond the anal sphincter to measure rectal temperature $\left(\mathrm{T}_{\mathrm{re}}\right)$ from which the rate of change of $\mathrm{T}_{\mathrm{re}}$ was calculated when the data were linear. That being from the final 10 minutes in each period, except during Work 
period 3 when data were obtained from 10 minutes into the work period onwards. As a conservative safety limit, participants ceased exercising when $\mathrm{T}_{\mathrm{re}}>39.0{ }^{\circ} \mathrm{C}$ but it is of interest to predict the time for $\mathrm{T}_{\mathrm{re}}$ to reach $40{ }^{\circ} \mathrm{C}$. Therefore, assuming that thermal balance would not be achieved and the measured rate of increase of $\mathrm{T}_{\mathrm{re}}$ was linear, predicted TT to a $\mathrm{T}_{\mathrm{re}}$ of $40^{\circ} \mathrm{C}\left(\right.$ from $\left.37.5^{\circ} \mathrm{C}\right)$ was calculated. This provides a clear, albeit partly extrapolated, calculation for the end user as to predicted TT that could theoretically be achieved whilst working at a constant intensity with no recovery periods.

Participants were instrumented with skin thermistors (Grant Instruments [UK] Ltd, UK) at four sites: calf, thigh, chest and upper arm, to estimate mean skin temperature $\left(\overline{\mathrm{T}}_{\mathrm{sk}}\right)$ and mean body temperature $\left(\overline{\mathrm{T}}_{\mathrm{b}}\right)$ in conjunction with $\mathrm{T}_{\mathrm{re}}$.

$$
\begin{gathered}
\overline{\mathrm{T}}_{\mathrm{sk}}=0.3\left(\mathrm{~T}_{\text {chest }}+\mathrm{T}_{\mathrm{arm}}\right)+0.2\left(\mathrm{~T}_{\text {thigh }}+\mathrm{T}_{\text {calf }}\right)\left[{ }^{\circ} \mathrm{C}\right] \quad \text { (Ramanathan 1964) } \\
\overline{\mathrm{T}}_{\mathrm{b}}=0.79\left(\mathrm{~T}_{\mathrm{re}}\right)+0.21\left(\overline{\mathrm{T}}_{\mathrm{sk}}\right)\left[{ }^{\circ} \mathrm{C}\right] \quad \text { (Colin et al. 1971) }
\end{gathered}
$$

Additional skin thermistors were also placed on the cheek and the right finger pad to monitor cheek temperature $\left(\mathrm{T}_{\text {cheek }}\right)$ and finger temperature $\left(\mathrm{T}_{\text {finger }}\right)$. Heart rate (HR) was monitored by a three-lead electrocardiogram (ECG) attached to the chest with gel electrodes (Blue Sensor SP, Ambu, DK) and a conservative safety limit was HR > 10 beats. min $^{-1}$ below age predicted maximum. The ECG and human temperature data were continuously transmitted wirelessly to a data acquisition system (Sharktooth System, MIE Medical Research Ltd, UK). Post-instrumentation, participants donned CB equipment relevant to their condition. A dressed weight was taken.

\section{Test Procedure}

After instrumentation and donning of equipment, participants were escorted into the 
environmental chamber and undertook ten minutes of seated rest before the commencement of light to moderate exercise of stepping to a height of $22.5 \mathrm{~cm}$ at a rate of 12 steps. $\min ^{-1}$ (Figure 1). To avoid dehydration, participants were provided with 250 $\mathrm{mL}$ of moderately chilled water (approximately $15{ }^{\circ} \mathrm{C}$ ) every 20 minutes. To determine whether metabolic heat production was equal between conditions due to the matched weight, work rate $\dot{\mathrm{V}} \mathrm{O}_{2}$ (STPD), was determined from expired air collected in Douglas bags in the last minute or 2 minutes of each work and recovery period. Subjective measures were taken every 20 minutes, and initially at baseline, using the Borg scale (1976) to represent a rating of perceived exertion (RPE) and visual analogue scales to quantify perceived whole body thermal comfort, thermal sensation and skin wettedness. On completion of each experiment clothed and nude masses were measured. The rate of whole body sweat evaporation and production $\left(\mathrm{L} . \mathrm{hr}^{-1}\right)$ were calculated from the difference in clothed and nude mass accounting for fluid intake as well as individual TT. The sweat evaporation / production ratio (SwE/P), which provides an indication of the efficiency of sweating, was calculated as a ratio of absolute sweat evaporation to absolute sweat production.

\section{Statistical Analysis and Data Handling}

All statistical analyses were conducted using Prism 6 (GraphPad, US) or SPSS (Version 22, IBM SPSS Statistics, US). Column statistics were conducted to check for normal distribution with the D'Agostino and Pearson normality test. One-way or two-way repeated measures ANOVA were conducted with significant differences located using a Tukey post-hoc test with multiplicity adjusted p-values. Ordinal data (RPE) were subject to a factorial ANOVA with a condition (five) by time (three) comparison and post-hoc pairwise analysis was performed with a Bonferroni correction for multiple 
comparisons. For all statistical analyses presented, an alpha ( $\alpha$ ) value of $\alpha<0.05$ was considered statistically significant. Unless otherwise stated, data are presented as mean (standard error of the mean [SEM]). Data were statistically compared at 10-minute intervals to the time point at which the first participant ceased stepping (110 minutes) for all conditions. Recovery 3 data were analysed separately. For measures when Recovery 3 data were linear, such as $\mathrm{T}_{\mathrm{re}}$, the hourly rate of change was calculated based upon the rate of rise or fall from 10 minutes into Recovery 3 onwards to ensure linearity. For measures when data were not linear during Recovery 3, such as HR, the change in recovery $(\mathrm{r} \Delta)$ data were calculated for the final 10 minutes of Recovery 3. Direct comparisons at discrete time intervals during Recovery 3 could not be made without introducing a bias into the results as participants spent varying durations in the chamber (Work 3) before reaching Recovery 3.

\section{Results}

\section{Oxygen Uptake}

$\mathrm{N}_{\mathrm{G}}$ resulted in a marginally $\left(0.84 \mathrm{~mL} \cdot \mathrm{kg}^{-1} \cdot \mathrm{min}^{-1}\right)$ greater mean $\dot{\mathrm{VO}}_{2}$ during Work 2 compared to $\mathrm{CON}(\mathrm{p}<0.01)$. The mean $\dot{\mathrm{V}}_{2}$ during Work 1 for $\mathrm{N}_{\mathrm{OB}}$ was again marginally $\left(0.81 \mathrm{~mL} \cdot \mathrm{kg}^{-1} \cdot \mathrm{min}^{-1}\right)$ greater compared to CON $(\mathrm{p}<0.05)$.

\section{Tolerance Time}

Table II. Participant completion data with actual and predicted mean (SEM) tolerance times whilst stepping and recovering in an environmental chamber controlled at $40.5{ }^{\circ} \mathrm{C}$ and $20 \%$ rh $(\mathrm{n}=13) .{ }^{*} \mathrm{p}<0.05,{ }^{* * *} \mathrm{p}<0.001$ vs. CON; ${ }^{\#} \mathrm{p}<0.05,{ }^{\# \#} \mathrm{p}<0.01$ vs. $\mathrm{N}_{\mathrm{G}}$.

$\mathrm{N}_{\mathrm{G}}$ resulted in the greatest number of participants completing the full 60 minutes of 
stepping during Work 3 (7 participants), with $\mathrm{N}_{\mathrm{OB}}$ the least (2 participants) after $\mathrm{CON}$ (1 participant) (Table II). $\mathrm{N}_{\mathrm{G}}$ was the only condition that resulted in an extended TT during Work 3 of 9.2 minutes $(21.3 \%)$ compared to $\mathrm{CON}(\mathrm{p}<0.05)$. Compared to CON, all conditions except $\mathrm{N}_{\mathrm{OB}}$, resulted in an extended predicted TT from a $\mathrm{T}_{\mathrm{re}}$ of $37.5^{\circ} \mathrm{C}$ to a $\mathrm{T}_{\mathrm{re}}$ of $39.5{ }^{\circ} \mathrm{C}$ and $40.0{ }^{\circ} \mathrm{C}(\mathrm{p}<0.05)$. As TT provides an indication of the overall level of strain, an additional comparison was calculated for this variable which highlighted that predicted TT to a $\mathrm{T}_{\mathrm{re}}$ of $39.5^{\circ} \mathrm{C}$ and $40.0{ }^{\circ} \mathrm{C}$ was also extended during $\mathrm{N}_{\mathrm{G}}$ compared to all conditions $(\mathrm{p}<0.05)$. Furthermore, the $\mathrm{T}_{\mathrm{re}}$ if the full 60 minutes of Work 3 were completed was predicted for each condition and the results indicated that the final predicted $\mathrm{T}_{\mathrm{re}}$ of all conditions except $\mathrm{N}_{\mathrm{OB}}$ were reduced compared to $\mathrm{CON}$ $\left(39.44[0.11]{ }^{\circ} \mathrm{C}\right)$. Additionally, $\mathrm{N}_{\mathrm{R}}\left(39.17[0.08]{ }^{\circ} \mathrm{C}, \mathrm{p}<0.001\right), \mathrm{N}_{\mathrm{BAL}}\left(39.22[0.09]{ }^{\circ} \mathrm{C}\right.$, $\mathrm{p}<0.05)$ and $\mathrm{N}_{\mathrm{G}}\left(39.02[0.07]{ }^{\circ} \mathrm{C}, \mathrm{p}<0.001\right)$ all displayed a significantly reduced predicted $\mathrm{T}_{\mathrm{re}}$ compared to $\mathrm{N}_{\mathrm{OB}}\left(39.34[0.10]^{\circ} \mathrm{C}\right)$.

In the cases of non-completion of the 60 -minute $3^{\text {rd }}$ work period, the prime reason for stopping was reaching the $\mathrm{T}_{\mathrm{re}}$ stopping limit of $39.0^{\circ} \mathrm{C}$ which occurred in 10 of the 13 participants in $\mathrm{CON}, \mathrm{n}=5$ for $\mathrm{N}_{\mathrm{R}}, \mathrm{n}=8$ for $\mathrm{N}_{\mathrm{BAL}}, \mathrm{n}=3$ for $\mathrm{N}_{\mathrm{G}}$, and $\mathrm{n}=8$ for $N_{\mathrm{OB}}$. The other withdrawals were either for reaching the HR limit $\left(n=1\right.$ for $N_{R}, n=1$ for $\mathrm{N}_{\mathrm{G}}, \mathrm{n}=2$ for $\mathrm{N}_{\mathrm{OB}}$ ) or wishing to stop due to fatigue ( $\mathrm{n}=2$ for CON, $\mathrm{n}=2$ for $\mathrm{N}_{\mathrm{R}}, \mathrm{n}$ $=2$ for $\mathrm{N}_{\mathrm{G}}, \mathrm{n}=1$ for $\mathrm{N}_{\mathrm{OB}}$ ).

\section{Whole Body Sudomotor Response}

Figure 2. Mean (SEM) whole body rate of sweat production (solid) and evaporation (checked) and the sweat evaporation / production ratio (stripes) whilst stepping and recovering in $40.5{ }^{\circ} \mathrm{C}$ and $20 \%$ rh when wearing varying combinations of protective ancillary items $(\mathrm{n}=13) .{ }^{*} \mathrm{p}<0.05,{ }^{* * * *} \mathrm{p}<0.0001 \mathrm{vs}$. CON. 
When adjusted for individual TT the mean rate of sweat evaporation during $\mathrm{N}_{\mathrm{BAL}}$ was increased by $10 \%$ compared to CON (0.33 [0.02] L.hr ${ }^{-1}$ vs. 0.30 [0.02] L.hr $\left.{ }^{-1}, \mathrm{p}<0.05\right)$. Mean SwE/P was also improved by $8.1 \%$ during $\mathrm{N}_{\mathrm{BAL}}$ compared to CON (55.32 [2.11] $\%$ vs. $47.25[2.68] \%, \mathrm{p}<0.0001) . \mathrm{N}_{\mathrm{OB}}$ resulted in an improved mean whole body SwE/P by $6.7 \%$ compared to CON (53.98 [2.01] \% vs. 47.25 [2.68] \%, p < 0.05).

\section{Rectal Temperature}

Figure 3. Mean (SEM) rate of change of rectal temperature whilst stepping and recovering in $40.5{ }^{\circ} \mathrm{C}$ and $20 \%$ rh when wearing varying combinations of protective ancillary items $(\mathrm{n}=13) .{ }^{*} \mathrm{p}<0.05,{ }^{* *} \mathrm{p}<0.01,{ }^{* * *} \mathrm{p}<0.001,{ }^{* * * *} \mathrm{p}<0.0001$ vs. CON.

For $\mathrm{N}_{\mathrm{G}}$ the mean rate of change of $\mathrm{T}_{\mathrm{re}}$ was attenuated by $19.0 \%$ during Work $2(1.11$ $[0.08]{ }^{\circ} \mathrm{C} . h r^{-1}$ vs. $\left.1.37[0.09]{ }^{\circ} \mathrm{C} . \mathrm{hr}^{-1}, \mathrm{p}<0.05\right)$ and by $20.3 \%$ during Work 3 (1.45 $[0.05]{ }^{\circ} \mathrm{C} . h r^{-1}$ vs. $\left.1.82[0.06]{ }^{\circ} \mathrm{C} . \mathrm{hr}^{-1}, \mathrm{p}<0.001\right)$ compared to CON. Cooling was evident during Recovery 3 for $\mathrm{N}_{\mathrm{G}}$ compared to $\mathrm{CON}\left(-0.25[0.14]{ }^{\circ} \mathrm{C} . \mathrm{hr}^{-1}\right.$ vs. $0.03[0.07]{ }^{\circ} \mathrm{C} . \mathrm{hr}^{-1}$, $\mathrm{p}<0.05)$. The mean rate of rise of $\mathrm{T}_{\mathrm{re}}$ was attenuated only during Work 2 for $\mathrm{N}_{\mathrm{R}}$ by $29.9 \%$ compared to $\mathrm{CON}\left(0.96[0.06]^{\circ} \mathrm{C}^{-h^{-1}}\right.$ vs. $\left.1.37[0.09]^{\circ} \mathrm{C} . \mathrm{hr}^{-1}, \mathrm{p}<0.0001\right)$. Again, it was only during Work 2 that the mean rate of rise of $\mathrm{T}_{\mathrm{re}}$ was attenuated during $\mathrm{N}_{\mathrm{BAL}}$ compared to CON by $24.8 \%\left(1.03[0.10]{ }^{\circ} \mathrm{C} . \mathrm{hr}^{-1}\right.$ vs. $\left.1.37[0.09]^{\circ} \mathrm{C} . \mathrm{hr}^{-1}, \mathrm{p}<0.01\right)$.

\section{Mean Body Temperature}

Figure 4. Average change in mean body temperature whilst stepping and recovering in $40.5{ }^{\circ} \mathrm{C}$ and $20 \%$ rh when wearing varying combinations of protective ancillary items $(n=13)$. Data were truncated at the last point where $n=13$ for each condition. 
During $\mathrm{N}_{\mathrm{G}}, \overline{\mathrm{T}}_{\mathrm{b}}$ was lowered compared to $\mathrm{CON}$ from 90 minutes $\left(1.24[0.10]{ }^{\circ} \mathrm{C}\right.$ vs. 1.36 $\left.[0.08]{ }^{\circ} \mathrm{C}, \mathrm{p}<0.05\right)$ to 110 minutes $\left(1.59[0.09]{ }^{\circ} \mathrm{C} v s .1 .76[0.08]{ }^{\circ} \mathrm{C}, \mathrm{p}<0.001\right)$. This was by a maximum of $0.17{ }^{\circ} \mathrm{C}(9.7 \%)$. During Recovery 3 , the mean $\mathrm{r} \Delta \overline{\mathrm{T}}_{\mathrm{b}}$ was improved by $0.09(0.03){ }^{\circ} \mathrm{C}$ for $\mathrm{N}_{\mathrm{G}}$ compared to $\mathrm{CON}(\mathrm{p}<0.05) . \mathrm{N}_{\mathrm{R}}$ lowered $\overline{\mathrm{T}}_{\mathrm{b}}$ during Work 3 at 100 minutes $\left(1.35[0.09]{ }^{\circ} \mathrm{C} v s .1 .47[0.08]{ }^{\circ} \mathrm{C}, \mathrm{p}<0.05\right)$ and 110 minutes $\left(1.59[0.09]{ }^{\circ} \mathrm{C} v s .1 .76[0.08]{ }^{\circ} \mathrm{C}, \mathrm{p}<0.001\right)$ compared to CON. This was by a maximum of $0.17{ }^{\circ} \mathrm{C}(9.7 \%)$. $\mathrm{N}_{\mathrm{BAL}}$ lowered $\overline{\mathrm{T}}_{\mathrm{b}}$ compared to $\mathrm{CON}$ from 90 minutes $\left(1.23[0.11]^{\circ} \mathrm{C}\right.$ vs. $\left.1.36[0.08]{ }^{\circ} \mathrm{C}, \mathrm{p}<0.05\right)$ to 110 minutes $\left(1.60[0.11]{ }^{\circ} \mathrm{C}\right.$ vs. 1.76 $\left.[0.08]^{\circ} \mathrm{C}, \mathrm{p}<0.01\right)$. This was by a maximum of $0.16{ }^{\circ} \mathrm{C}(9.1 \%)$. During Recovery 3 , the mean $\mathrm{r} \Delta \overline{\mathrm{T}}_{\mathrm{b}}$ for $\mathrm{N}_{\mathrm{BAL}}$ was improved by $0.06(0.02){ }^{\circ} \mathrm{C}$ compared to $\mathrm{CON}(\mathrm{p}<0.01)$.

\section{Local Skin Temperature}

\section{Cheek}

During the first 30 minutes into the protocol, $\mathrm{N}_{\mathrm{R}}$ resulted in a significantly greater mean $\mathrm{T}_{\text {cheek }}$ compared to $\mathrm{CON}$ and all other conditions by a maximum of $1.76{ }^{\circ} \mathrm{C}$ (36.54 [0.12] ${ }^{\circ} \mathrm{C} v s . \mathrm{CON}: 34.78\left[0.31{ }^{\circ} \mathrm{C}, \mathrm{p}<0.0001\right)$.

\section{Finger}

$\mathrm{N}_{\mathrm{G}}$ did not significantly affect $\mathrm{T}_{\text {finger }}$ or $\mathrm{r} \Delta \mathrm{T}_{\text {finger }}$ during Recovery 3 even though a trend was apparent for a lowered $\mathrm{T}_{\text {finger }}$ during $\mathrm{N}_{\mathrm{G}}$ compared to CON later in the protocol $(\mathrm{p}=$ 0.057). $\mathrm{N}_{\mathrm{BAL}}$ resulted in a lowered $\mathrm{T}_{\text {finger }}$ at 10 minutes compared to CON (34.72 [0.89] $\left.{ }^{\circ} \mathrm{C} v s .35 .35[0.73]{ }^{\circ} \mathrm{C}, \mathrm{p}<0.05\right)$. At 20 minutes into the protocol, $\mathrm{T}_{\text {finger }}$ was lowered during $\mathrm{N}_{\mathrm{OB}}$ compared to $\mathrm{CON}\left(36.27[0.64]{ }^{\circ} \mathrm{C}\right.$ vs. $\left.36.91[0.15]{ }^{\circ} \mathrm{C}, \mathrm{p}<0.05\right)$. 


\section{Heart Rate}

Figure 5. Mean heart rate whilst stepping and recovering in $40.5^{\circ} \mathrm{C}$ and $20 \%$ rh when wearing varying combinations of protective ancillary items $(n=13)$. Data were truncated at the last point where $\mathrm{n}=13$ for each condition.

$\mathrm{N}_{\mathrm{R}}$ resulted in lowered mean HR compared to CON at 90 minutes (99 [4] beats. $\mathrm{min}^{-1}$ vs. 107 [4] beats.min $\left.{ }^{-1}, \mathrm{p}<0.05\right)$ and 110 minutes $\left(142\right.$ [4] beats. $\min ^{-1}$ vs. 150 [4] beats. $\min ^{-1}, \mathrm{p}<0.01$ ) by a maximum of 8 beats. $\min ^{-1}$. Compared to CON, mean HR for $\mathrm{N}_{\mathrm{BAL}}$ was lowered during Work 2 at 60 minutes (111 [4] beats. min $^{-1}$ vs. 118 [4] beats. $\left.\min ^{-1}, \mathrm{p}<0.05\right)$, Work 3 at 100 minutes (131 [3] beats. $\min ^{-1} v s .139$ [4] beats.min $\left.{ }^{1}, \mathrm{p}<0.05\right)$ and 110 minutes $\left(144\right.$ [4] beats. $\min ^{-1}$ vs. 150 [4] beats.min $\left.{ }^{-1}, \mathrm{p}<0.05\right)$ with an enhanced reduction in mean HR during Recovery 2 at 80 minutes (90 [5] beats. min $^{-1}$ vs. 98 [4] beats. $\left.\min ^{-1}, \mathrm{p}<0.05\right)$. This was by a maximum of 8 beats. $\mathrm{min}^{-1}$. There were no significant differences in heart rate between CON and $\mathrm{N}_{\mathrm{G}}$ nor $\mathrm{CON}$ and $\mathrm{N}_{\mathrm{OB}}$ throughout the protocol, although there was a trend for heart rate to be lower during $\mathrm{N}_{\mathrm{G}}$ compared to CON at 110 minutes (CON: 150 [4] beats.min ${ }^{-1}$ vs. $\mathrm{N}_{\mathrm{G}}: 144$ [5] beats.min ${ }^{-}$ $\left.{ }^{1}, \mathrm{p}=0.058\right)$.

\section{Perceptual Measures}

Significant differences were only located for perceived whole body thermal sensation, thermal comfort and skin wettedness. There were no significant differences for the mean RPE between any conditions.

\section{Thermal Sensation}

Significant differences to the mean perceived thermal sensation were only noted for $\mathrm{N}_{\mathrm{BAL}}$. Initially at baseline, participants reported feeling less warm during $\mathrm{N}_{\mathrm{BAL}}$ 
compared to CON (11.42 [0.70] vs. 12.80 [0.74], $\mathrm{p}<0.01) . \mathrm{N}_{\mathrm{BAL}}$ also improved mean reporting's of thermal sensation compared to CON 20 minutes into Work 3 (16.12 [0.31] vs. $17.22[0.42], \mathrm{p}<0.05)$ and at the end of Recovery $3(16.13$ [0.70] vs. 17.71 [0.47], $\mathrm{p}<0.01)$

\section{Thermal Comfort}

Figure 6. Mean (SEM) perceived thermal comfort whilst stepping and recovering in $40.5^{\circ} \mathrm{C}$ and $20 \% \mathrm{rh}$ when wearing varying combinations of protective ancillary items $(\mathrm{n}=13) .{ }^{*} \mathrm{p}<0.05, \stackrel{* *}{\mathrm{p}}<0.01, \stackrel{* * *}{\mathrm{p}}<0.001$ vs. CON.

Participants reported feeling less thermally uncomfortable during $\mathrm{N}_{\mathrm{G}}$ compared to CON 20 minutes into Work $3(-1.26[0.96] v s .-3.94[0.79], \mathrm{p}<0.01)$ and at the end of Recovery $3(-2.57$ [1.30] vs. -5.52 [1.17], $\mathrm{p}<0.001)$ where participants' reported feeling "just uncomfortable" during $\mathrm{N}_{\mathrm{G}}$ compared to "uncomfortable" during CON. It was only at the end of Recovery 3 that participants rated $\mathrm{N}_{\mathrm{BAL}}$ less thermally uncomfortable than CON (-3.31 [1.14] vs. -5.52 [1.17], p < 0.05). Again, it was only at the end of Recovery 3 that participants rated $\mathrm{N}_{\mathrm{OB}}$ less thermally uncomfortable compared to CON (-3.52 [1.50] vs. $-5.52[1.17], \mathrm{p}<0.05)$.

Skin Wettedness

$\mathrm{N}_{\mathrm{BAL}}$ was reported as feeling less wet compared to $\mathrm{CON}$ at the end of Work 2 (11.99 [0.79] vs. 13.78 [0.94], $\mathrm{p}<0.05)$ and 20 minutes into Work $3(14.65$ [0.72] vs. $16.85[0.88], \mathrm{p}<0.01)$ whereby participants reported feeling "very damp" $\left(\mathrm{N}_{\mathrm{BAL}}\right)$ compared to "wet" (CON). $\mathrm{N}_{\mathrm{OB}}$ was reported as feeling less wet compared to CON 20 minutes into Work 3 only (15.00 [0.86] vs. 16.85 [0.88], $\mathrm{p}<0.05)$. 


\section{Discussion}

Ancillary items that are MVIP worn by warfighters to protect against contaminating agents impose a thermal burden, which was lessened to the greatest degree when the gloves were not worn and to the least degree when the overboots were not worn, as hypothesized. Exposing the hands attenuated the rate of rise of $\mathrm{T}_{\mathrm{re}}$ during the final work period compared to $\mathrm{CON}$, which resulted in the greatest number of participants completing the protocol and extended TT during continuous work. The exact mechanism responsible for the large heat dissipation at the hands was not directly measured in this study. However, we speculate that due to the high density of sweat glands, particularly on the volar surfaces (Taylor and Machado-Moreira 2013), there was a high rate of sweat production with concomitant support for large increases in cutaneous blood flow (Grant and Bland 1931; Hales 1985) distributing the cooled extremity blood back to the core. Although the surface area of the hands is small (approximately $4.6 \%$ of total body surface area [Yu, Hsu, and Chen 2008]), due to the nature of the exercise prescribed (stepping) and the consequent hand swinging motion that accompanies stepping, there was probably a greater degree of forced evaporative cooling from the hands (although not directly measured).

Any substantial quantity of sweat produced or evaporated when the hands were exposed was not expressed in the whole body measure and subsequent studies should measure local sweat rates. Nonetheless, this suggests that the mechanism was not only sudomotor and subsequent studies should examine local cutaneous blood flow to quantify the contribution of the vasomotor component. Furthermore, there was no significant lowering of $\mathrm{T}_{\text {finger }}$, that would be indicative of evaporative cooling at the finger, when the gloves were not worn. It is most likely that this measure would have been balanced with heat gain from the warmer environment $\left(40.5^{\circ} \mathrm{C}\right)$ and arterial 
blood. Moreover, the finger thermistor was secured to the finger pad using thin waterproof adhesive but porous surgical tape, which may have partly inhibited evaporation of sweat directly from the site of $\mathrm{T}_{\text {finger }}$ measurement and might have fostered a slight insulative microclimate (Buono and Ulrich 1998). Whilst the rest of the hand was exposed, due to the tape, $\mathrm{Tf}_{\text {inger }}$ might not have provided an accurate representation of total hand temperature, but should be similar, and indicate changes similarly.

Exposing the hands extended predicted TT from a hypothetical starting $\mathrm{T}_{\mathrm{re}}$ of $37.5^{\circ} \mathrm{C}$ to a $\mathrm{T}_{\mathrm{re}}$ of $39.5^{\circ} \mathrm{C}$ and $40.0{ }^{\circ} \mathrm{C}$ by 17.0 minutes and 21.3 minutes respectively compared to $\mathrm{CON}$ and was also significantly extended compared to all other conditions. This would equate to the patrolling individual covering an extra $1.12 \mathrm{~km}$ or $1.41 \mathrm{~km}$ (if walking at a light intensity at a speed of $1.11 \mathrm{~m} . \mathrm{s}^{-1}$ with a hypothetical gradient of $0 \%$ [McLellan, Meunier, and Livingstone 1992]) before there is an increased risk of heat stroke causing serious systemic dysfunction (Knochel and Reed 1994) simply by permitting evaporative cooling from the hands alone. Additionally, the individual would, where possible, stop exercising and recover when the thermoregulatory strain of $\mathrm{CB}$ equipment becomes overwhelming. Therefore, the augmented rate of cooling during Recovery $3\left(-0.25^{\circ} \mathrm{C} . \mathrm{hr}^{-1}\right)$ when the hands were exposed would allow for dynamic and extended operations if recovery periods are feasible, rather than operational TT being limited by, among other factors, metabolic rate and the time taken to reach microclimate saturation.

The physiological improvements to thermoregulatory strain during $\mathrm{N}_{\mathrm{G}}$ were also detected perceptually. It is important to note that perceptual improvements were identified during Recovery 3 even though participants had, by that time, spent a longer duration in the heat (an additional 9.2 minutes) during $\mathrm{N}_{\mathrm{G}}$ compared to $\mathrm{CON} . \mathrm{N}_{\mathrm{G}}$ 
resulted in participants feeling less thermally uncomfortable compared to $\mathrm{CON}$ and whilst the somatosensory homunculus indicates that the hands (and fingers) provide a large amount of sensory feedback to the brain, the homunculus also indicates that the face is equally as sensitive (Penfield and Boldrey 1937), a result that was not identified in the current study when rating perceived thermal comfort. Thus, perhaps when considering thermoreception in isolation to other sensory cues, a different weighting / homunculus would be identified. Body areas possess varying limits of local thermal comfort and as suggested by Fukazawa and Havenith (2009) the periphery (arms and thighs) possess a higher sensitivity of thermal discomfort to skin wettedness compared to the torso. The current study found that thermal comfort was improved compared to $\mathrm{CON}$ for $\mathrm{N}_{\mathrm{G}}$ during both exercise and recovery but was only improved for $\mathrm{N}_{\mathrm{BAL}}$ during recovery, although no significant differences were identified between $\mathrm{N}_{\mathrm{G}}$ and $\mathrm{N}_{\mathrm{BAL}}$. Nonetheless, these results taken together with the sensory cortical homunculus (Penfield and Boldrey 1937) suggest that the extremities such as the hands could potentially possess a higher sensitivity of thermal discomfort than the torso and perhaps even the arms and thighs. These findings also extend the work of Fukazawa and Havenith (2009) to include analysis of regional thermal discomfort during recovery.

$\mathrm{N}_{\mathrm{R}}$ and $\mathrm{N}_{\mathrm{BAL}}$ resulted in equal numbers of participants completing the protocol. Considering that the surface area of the torso is approximately 14 times that of the face (manikin Newton, Thermetrics, US; Weiner 1945), it would appear that exposing the face resulted in thermoregulatory improvements that are greater than expected for its surface area. However, whilst the face was directly exposed to the environment when the respirator was not worn, the torso, when the BAL was not worn, was still covered by the protective suit that possesses a low air permeability. Nonetheless, this result still indicates the practical, end-user benefits of improving the MVP of the respirator or BA. 
During the first 30 minutes of the protocol, $N_{R}$ resulted in a greater $T_{\text {cheek }}$ as the exposed facial skin was gaining heat from the warmer ambient environment. For the remainder of the protocol, $\mathrm{T}_{\text {cheek }}$ was not different whether the respirator was worn or not. Again we acknowledge the limitation associated with the use of tape to attach the cheek thermistor. Additional calculations identified that if all participants had completed the protocol, $\mathrm{T}_{\mathrm{re}}$ would have been $0.27^{\circ} \mathrm{C}$ and $0.42{ }^{\circ} \mathrm{C}$ cooler during $\mathrm{N}_{\mathrm{R}}$ and $\mathrm{N}_{\mathrm{G}}$ respectively compared to $\mathrm{CON}$, with final $\mathrm{T}_{\mathrm{re}}$ during $\mathrm{N}_{\mathrm{G}}$ also being significantly lower compared to $\mathrm{N}_{\mathrm{R}}$. This highlights the reduction in thermoregulatory strain when evaporation from the hands was permitted compared to the face, most likely because the hands are approximately 1.7 times larger than the face (manikin Newton, Thermetrics, US; Yu, Hsu, and Chen 2008). $\mathrm{N}_{\mathrm{R}}$ also lowered HR compared to CON which was most likely indicative of the lowered thermoregulatory strain (Figure 4), although HR was not significantly lowered during $\mathrm{N}_{\mathrm{G}}(\mathrm{p}=0.058)$. Therefore, there was another factor influencing HR other than purely thermoregulatory strain. Early work investigating physiological responses when wearing a respirator found that during two hours of exercise, HR was elevated when a respirator was worn even though core temperature (unspecified) was not significantly different, although $\overline{\mathrm{T}}_{\mathrm{sk}}$ was elevated (Robinson and Gerking 1945; quoted in Muza, 1986). An elevated HR when wearing a respirator could be associated with anxiety that some individuals might experience during exercise when the face is covered or even hyperventilation that can induce tachycardia (Morgan 1983). There were no significant improvements to any perceptual measures during $\mathrm{N}_{R}$ compared to $\mathrm{CON}$, which was unexpected as the face is greatly represented on the somatosensory homunculus (Penfield and Boldrey 1937) and more recently, Cotter and Taylor (2005) found that the face displayed a greater sudomotor and alliesthesial thermosensitivity compared to the upper and lower limbs and limb extremities. 
Measuring whole body, rather than local perceptual responses might explain this finding. Furthermore, the initial facial heat gain from the warmer environment may have resulted in negative thermal perceptual responses that were not overcome later. Nonetheless, the greatest reduction to perceptual thermoregulatory strain compared to $\mathrm{CON}$ was when the gloves or BAL were not worn and therefore we fail to reject our null hypothesis.

The torso does not possess as great a density of sweat glands as the hands and feet (Taylor and Machado-Moreira 2013), but due to its large surface area (approximately $39.5 \%$ of total body surface area [Weiner 1945]), it was expected that $\mathrm{N}_{\mathrm{BAL}}$ would greatly reduce whole body thermoregulatory strain. Therefore, the improved rate of sweat evaporation by $10 \%$ and the improved SwE/P by $8 \%$ compared to $\mathrm{CON}$ were not surprising. However, it was unexpected that there would be no significant impact on the rise or fall of $\mathrm{T}_{\mathrm{re}}$ during continuous work or recovery as a result of the enhanced rate of sweat evaporation, although $\mathrm{N}_{\mathrm{BAL}}$ did lower $\overline{\mathrm{T}}_{\mathrm{b}}$ compared to $\mathrm{CON}$ during Work 3 . Using the rate of cooling during Recovery $3\left(\mathrm{~N}_{\mathrm{BAL}}: 0.05\right.$ [0.17] ${ }^{\circ} \mathrm{C} . h r^{-1}, \mathrm{~N}_{\mathrm{G}}: 0.25[0.14]{ }^{\circ} \mathrm{C} . \mathrm{hr}^{-1}$ ), it can be predicted that for $\mathrm{T}_{\mathrm{re}}$ to cool by $0.5{ }^{\circ} \mathrm{C}$ it would take approximately 2 hours if the gloves were made completely MVP as opposed to 10 hours if the BAL was made completely MVP. $\mathrm{N}_{\mathrm{BAL}}$ also improved ratings of thermal sensation and skin wettedness. The torso is not often the site targeted for positive thermal alliesthesia, nor is greatly represented on the somatosensory homunculus (Penfield and Boldrey 1937). Although, in cool conditions Nakamura et al. (2008) found that humans would preferentially warm the chest and abdomen as opposed to the face, thus highlighting the sensitivity of the torso to thermal stimuli. In the current study, the detection of these perceptual measures (improved thermal sensation and skin wettedness) might possibly be explained by the large surface area of the torso. 
Although $\mathrm{N}_{\mathrm{OB}}$ improved the whole body $\mathrm{SwE} / \mathrm{P}$ by $6.7 \%$ compared to $\mathrm{CON}$ and resulted in participants feeling less wet and less thermally uncomfortable, there were no reductions to other markers of thermoregulatory strain. Furthermore, additional calculations predicted that if the full 60 minutes of Work 3 were completed, all conditions except $\mathrm{CON}$, would have displayed a significantly reduced $\mathrm{T}_{\mathrm{re}}$ compared to $\mathrm{N}_{\mathrm{OB}}$. Thus, making the overboots completely MVP would result in the least decrease to thermoregulatory strain compared to any other item as hypothesized. The minimal reductions to thermoregulatory strain were most likely because during $\mathrm{N}_{\mathrm{OB}}$ the feet were not exposed (as the hands or face were during $\mathrm{N}_{\mathrm{G}}$ or $\mathrm{N}_{\mathrm{R}}$ ), but were still covered by the socks and combat boots. It was unexpected that $\mathrm{N}_{\mathrm{OB}}$ would impact perceptual measures more so than physiological measures. However, it may be that the bulk and design of the overboots, possibly making stepping more cumbersome when worn, might have influenced perceptual responses.

\section{Conclusions}

The greatest decrease to thermoregulatory strain and improvement in TT in the heat in individuals wearing $\mathrm{CB}$ clothing occurred when the gloves were not worn. The least decrease to thermoregulatory strain occurred when overboots were not worn and not wearing a respirator had less impact on whole body perceptual responses than expected. Thermoregulatory strain when wearing military CB equipment in desert-like environments would decrease to the greatest extent if the gloves and BA were made MVP. We have shown that the user would benefit less if the respirator and overboots were made MVP.

Disclosure statement: The study was funded by the University of Portsmouth. The authors have no relevant financial or nonfinancial relationships to disclose. 


\section{References}

Borg, G. 1976. "Simple rating methods for estimation of perceived exertion." Physical Work and Effort, 39-46.

Buono, M. J., and R. L. Ulrich. 1998. "Comparison of mean skin temperature using covered versus uncovered contact thermistors." Physiological Measurement 19 (2): 297-300.

Colin, J., Timbal, J., Houdas, Y., Boutelier, C., and J. D. Guieu. 1971. “Computation of mean body temperature from rectal and skin temperatures." Journal of Applied Physiology 31 (3): 484-489.

Cotter, J., Zeyl, A., Keizer, E., and N. A. S. Taylor. 1996. "The role of local skin temperature in determining the perception of local and whole-body thermal state.” In Environmental Ergonomics Recent Progress and New Frontiers, edited by Shapiro, Y.M., Epstein, D.S., and Y. Jarusalem, 85-88. Tel Aviv: Israel Freund Publishing House Ltd.

Cotter, J. D., and N. A. S. Taylor. 2005. "The distribution of cutaneous sudomotor and alliesthesial thermosensitivity in mildly heat- stressed humans: An open- loop approach.” Journal of Physiology 565 (1): 335-345.

Frank, S. M., Raja, S. N., Bulcao, C. F., and D. S. Goldstein. 1999. "Relative contribution of core and cutaneous temperatures to thermal comfort and autonomic responses in humans." Journal of Applied Physiology 86 (5): 15881593.

Fukazawa, T., and G. Havenith. 2009. "Differences in comfort perception in relation to local and whole body skin wettedness." European Journal of Applied Physiology 106 (1): 15-24.

Grant, R., and E. Bland. 1931. "Observations on arteriovenous anastomoses in human skin and in the bird's foot with special reference to the reaction to cold." Heart $15(385): 1929-1931$.

Hales, J. 1985. "Skin arteriovenous anastomoses, their control and role in thermoregulation.” In Cardiovascular Shunts Alfred Benzon Symposium 21, 433-452. Munksgaard: Copenhagen.

Knochel, J., and G. Reed. 1994. "Disorders of heat regulation.” In Maxwell and Kleeman's Clinical Disorders of Fluid and Electrolyte Metabolism, edited by R. G. Narins, 1549-1590. McGraw-Hill: New York. 
Krauchi, K., and A. Wirz-Justice. 1994. "Circadian rhythm of heat production, heart rate, and skin and core temperature under unmasking conditions in men." American Journal of Physiology - Regulatory, Integrative and Comparative Physiology 267 (3): R819-R829.

Lind, A. R. 1963. "Tolerable limits for prolonged and intermittent exposures to heat." In Temperature: Its Measurement and Control in Science and Industry, edited by J. D. Hardy, 337-345. Reinhold: New York.

McLellan, T., Meunier, P., and S. Livingstone. 1992. "Influence of a new vapour protective clothing layer on physical work tolerance times at $40{ }^{\circ} \mathrm{C}$." Aviation, Space, and Environmental Medicine 63 (1): 107-113.

Montain, S. J., Sawka, M. N., Cadarette, B. S., Quigley, M. D., and J. M. McKay. 1994. "Physiological tolerance to uncompensable heat stress: Effects of exercise intensity, protective clothing, and climate.” Journal of Applied Physiology 77 (1): $216-222$.

Morgan, W. P. 1983. "Psychological problems associated with the wearing of industrial respirators: a review." American Industrial Hygiene Association Journal 44 (9): 671-676.

Mündel, T., Bunn, S. J., Hooper, P. L., and D. A. Jones. 2006. “The effects of face cooling during hyperthermic exercise in man: evidence for an integrated thermal, neuroendocrine and behavioural response." Experimental Physiology 92 (1): 187-195.

Muza, S.R., 1986. "A review of biomedical aspects of CB masks and their relationship to military performance." US Army Research Institute of Environmental Medicine: Natick, MA, USA.

Nadel, E. R., Mitchell, J. W., and J. A. J. Stolwijk. 1973. "Differential thermal sensitivity in the human skin." Pflügers Archiv 304 (1): 71-76.

Nakamura, M., Yoda, T., Crawshaw, L. I., Yasuhara, S., Saito, Y., Kasuga, M., Nagashima, K., and K. Kanosue. 2008. "Regional differences in temperature sensation and thermal comfort in humans." Journal of Applied Physiology 105 (1): 1897-1906.

Penfield, W., and E. Boldrey. 1937. "Somatic motor and sensory representation in the cerebral cortex of man as studied by electrical stimulation.” Brain 60 (4): 389443. 
Ramanathan, N. L. 1964. "A new weighting system for mean surface temperature of the human body." Journal of Applied Physiology 19 (3): 531-533.

Robinson, S., and S. D. Gerking. 1945. "Heat stress imposed by gas masks.” Vol. 26. Report. Office of Scientific Research and Development, U.S. War Research Agency: Washington, D.C.

Smith, C. J., and G. Havenith. 2011. "Body mapping of sweating patterns in male athletes in mild exercise-induced hyperthermia." European Journal of Applied Physiology 111 (7): 1391-1404.

Taylor, N. A. S., and C. A. Machado-Moreira. 2013. "Regional variations in transepidermal water loss, eccrine sweat gland density, sweat secretion rates and electrolyte composition in resting and exercising humans." Extreme Physiology \& Medicine 2 (1): 1-29.

Weiner, J. S. 1945. "The regional distribution of sweating.” Journal of Physiology 104 (1): 32-40.

Weiss, B. and V. G. Laties. 1961. "Behavioural thermoregulation.” Science 133 (3464): 1338-1344.

Yu, C. Y., Hsu, Y. W., and C. Y. Chen. 2008. "Determination of hand surface area as a percentage of body surface area by 3D anthropometry." Burns 34 (8): 11831189.

Yu, C. Y., and H. H. Tu. 2009. "Foot surface area database and estimation formula." Applied Ergonomics 40 (4): 767-774.

Zhang, H. 2003. "Human thermal sensation and comfort in transient and non-uniform thermal environments." Center for the Built Environment Ph.D. Thesis, University of California: Berkeley. 

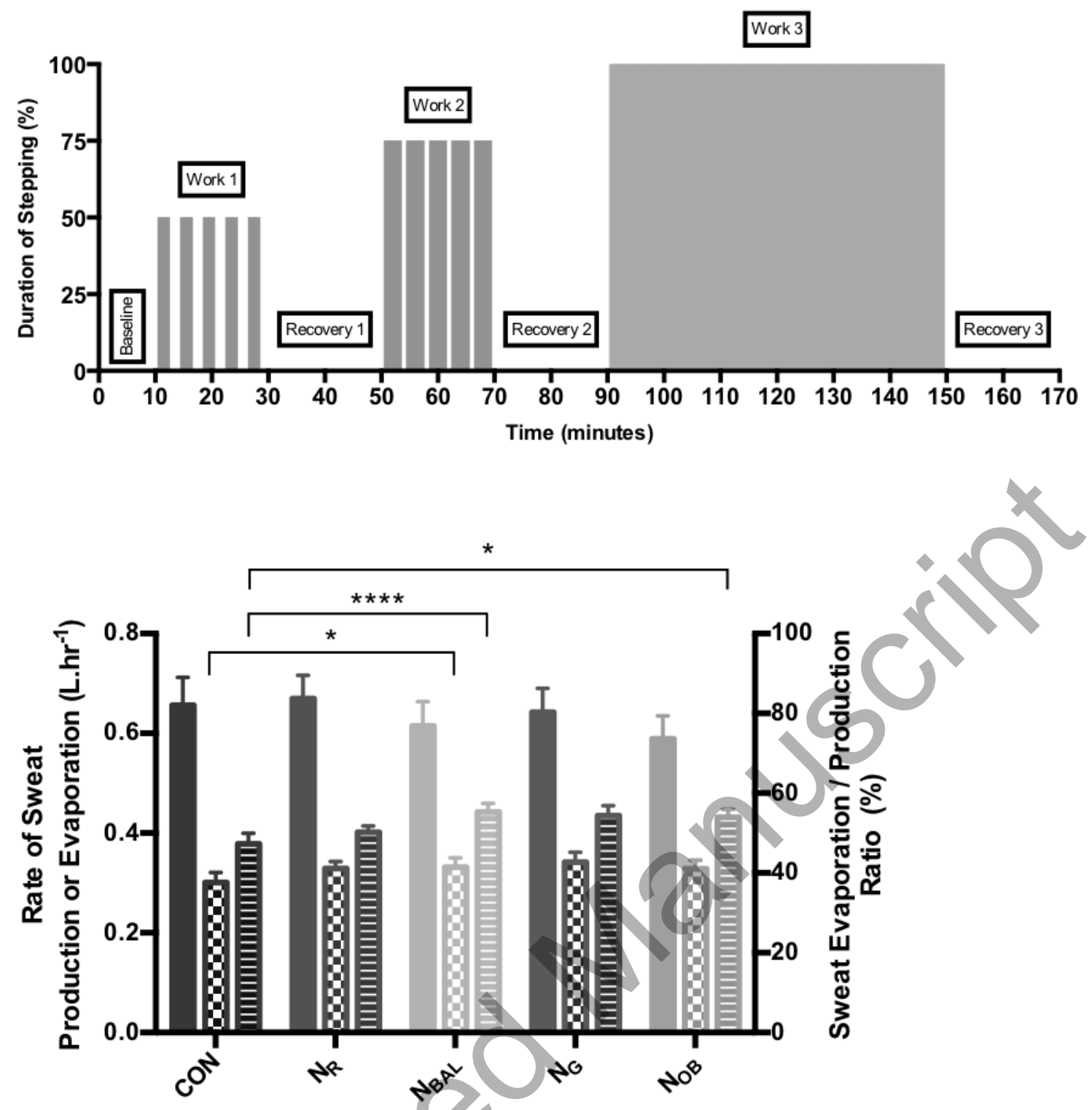


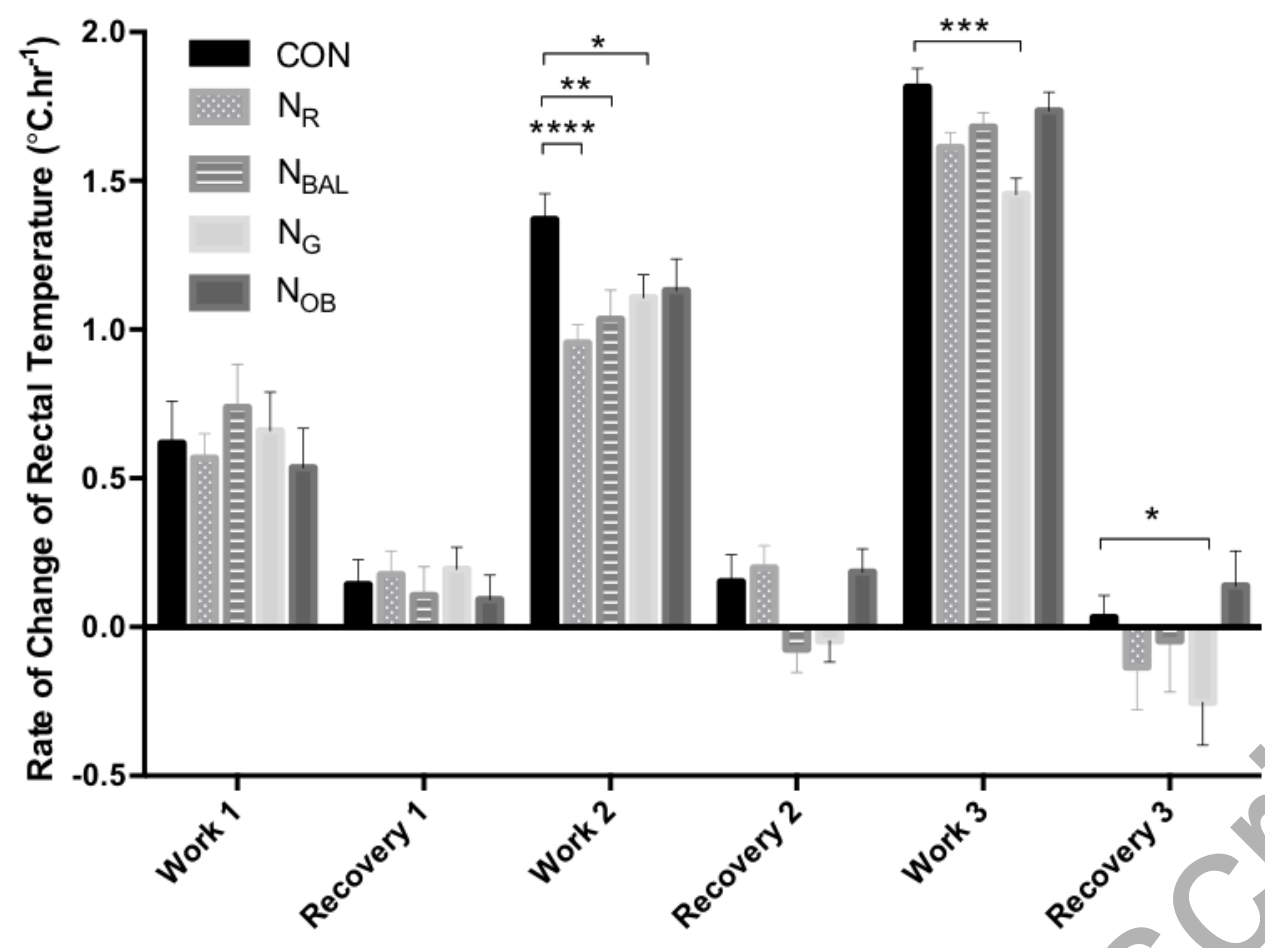

Time (minutes)

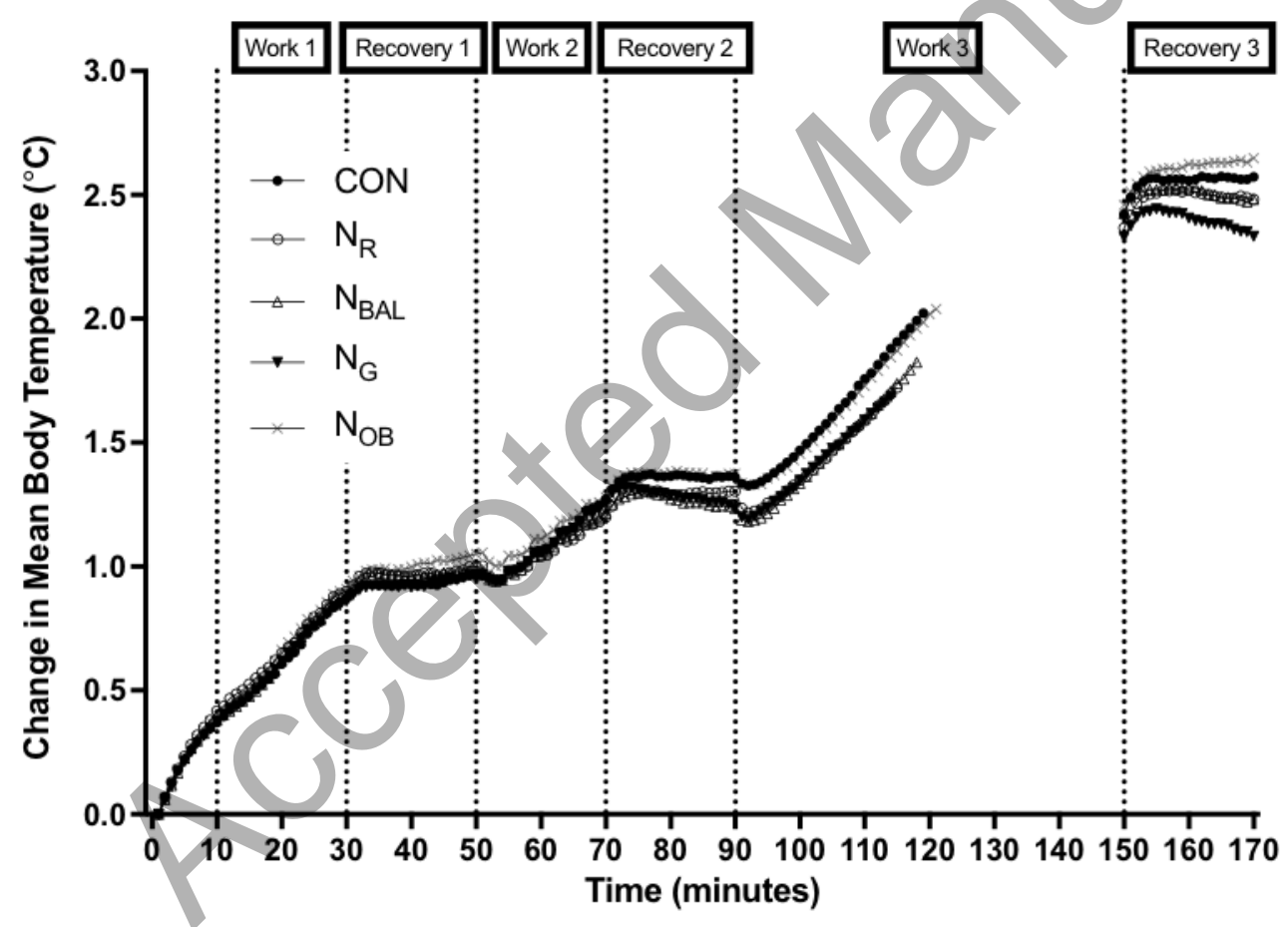



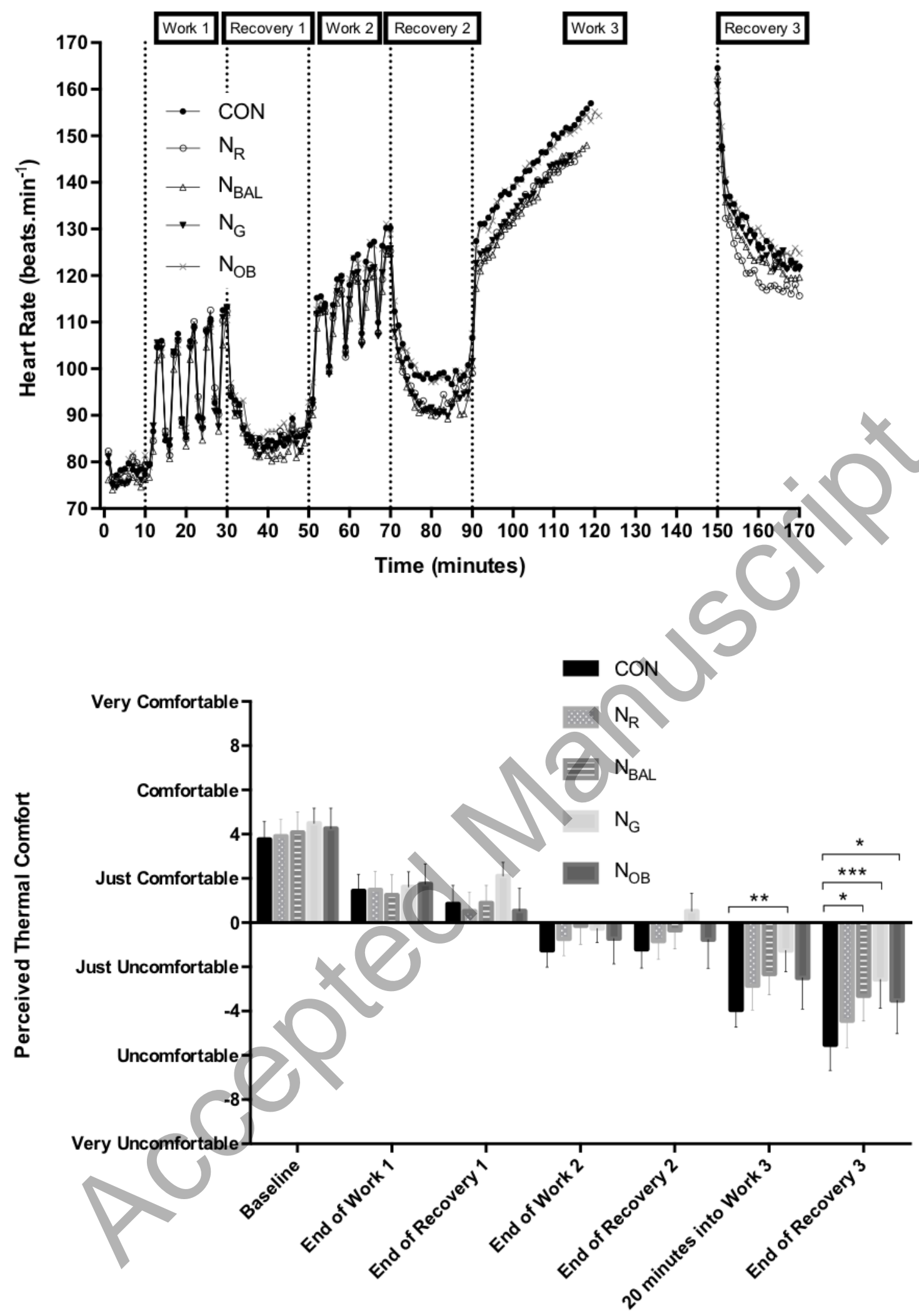


\begin{tabular}{|c|c|c|}
\hline \multirow{2}{*}{ CBRN PPE Item } & \multicolumn{2}{|r|}{ Item Characteristics } \\
\hline & Weight & Material \\
\hline $\begin{array}{l}\text { MiKVa CBRN PPE Suit } \\
\text { Size } 190 / 180 \mathrm{~cm} \\
\text { (height / chest) }\end{array}$ & $\begin{array}{l}\text { Trousers } 1.04 \mathrm{~kg} \\
\text { Jacket } 1.36 \mathrm{~kg}\end{array}$ & $\begin{array}{l}\text { Trouser and jacket 2-layer suit with integrated } \\
\text { hood. Tightly woven cotton ripstop outer with } \\
\text { activated carbon loaded woven liner fabric. The } \\
\text { lining is stitched to the outer at seams and edges } \\
\text { only, so air-gap can be present between layers. } \\
\text { Double-layer thickness ( } 1.3 \mathrm{~mm})\end{array}$ \\
\hline $\begin{array}{l}\text { General Service } \\
\text { Respirator (Large) }\end{array}$ & $0.85 \mathrm{~kg}$ & $\begin{array}{l}\text { Butyl rubber mask and plastic eye visor with butyl } \\
\text { rubber straps. Moisture Vapour Impermeable }\end{array}$ \\
\hline $\begin{array}{l}\text { Body Armour Liner } \\
\text { (Medium) }\end{array}$ & $0.18 \mathrm{~kg}$ & $\begin{array}{l}\text { Impermeable woven nylon (polyurethane blend } \\
\text { with a thermoplastic polyurethane coating). } \\
\text { Moisture Vapour Impermeable }\end{array}$ \\
\hline \multirow[b]{2}{*}{$\begin{array}{l}\text { Gloves } \\
\text { (Size } 10 \text { - Large) }\end{array}$} & Inner liner pair: $0.09 \mathrm{~kg}$ & Cotton \\
\hline & Outer glove pair: $0.15 \mathrm{~kg}$ & $\begin{array}{l}\text { Butyl rubber. Thicker towards fingers }(0.9 \mathrm{~mm}) \text { and } \\
\text { thinner to wrist }(0.5 \mathrm{~mm}) \text {. Moisture Vapour } \\
\text { Impermeable }\end{array}$ \\
\hline $\begin{array}{l}\text { Overboots } \\
\text { (Extra-large) }\end{array}$ & Pair: $1.31 \mathrm{~kg}$ & $\begin{array}{l}\text { Butyl rubber. Thickness varies between } 1.1 \mathrm{~mm} \text { to } \\
2.4 \mathrm{~mm} \text {, with a thicker tread-sole. Moisture Vapour } \\
\text { Impermeable. }\end{array}$ \\
\hline Combat Boots (Size 7) & $1.296 \mathrm{~kg}$ (pair) & $\begin{array}{l}\text { Leather and } 1150 \text { Denier Nylon Upper } \\
\text { Quick Drying and Breathable Lining } \\
\text { Non-slippery and Oil Resistant Rubber Outsole } \\
\text { Composite Toecap }\end{array}$ \\
\hline
\end{tabular}

Note: Total clothing mass for CON for the sizes given above is $6.276 \mathrm{~kg}$. 


\begin{tabular}{|c|c|c|c|c|}
\hline Condition & $\begin{array}{c}\text { Number of } \\
\text { Participants } \\
\text { Completing the } \\
\text { Protocol (n / } \\
\text { 13) }\end{array}$ & $\begin{array}{c}\text { Mean } \\
\text { (SEM) TT } \\
\text { during } \\
\text { Work 3 } \\
\text { (minutes) }\end{array}$ & $\begin{array}{c}\text { Mean (SEM) } \\
\text { Predicted TT from } \\
\text { a } \mathrm{T}_{\text {re }} \text { of } 37.5^{\circ} \mathrm{C} \text { to } \\
39.5^{\circ} \mathrm{C} \text { (minutes) }\end{array}$ & $\begin{array}{c}\text { Mean (SEM) } \\
\text { Predicted TT from } \\
\text { a } \mathrm{T}_{\text {re }} \text { of } 37.5^{\circ} \mathrm{C} \text { to } \\
\mathbf{4 0 . 0}{ }^{\circ} \mathrm{C} \text { (minutes) }\end{array}$ \\
\hline $\mathrm{CON}$ & 1 & $43.2(2.5)$ & $68.4(2.4)$ & $85.2(2.9)$ \\
\hline $\mathbf{N}_{\mathbf{R}}$ & 5 & $50.5(3.2)$ & $76.6(2.4)^{\text {*\# }}$ & $95.5(2.9)^{\text {*\# }}$ \\
\hline $\mathbf{N}_{\text {BAL }}$ & 5 & $51.4(2.9)$ & $73.5(2.2)^{* \# \#}$ & $91.7(2.7)^{* \# \#}$ \\
\hline $\mathbf{N}_{\mathbf{G}}$ & 7 & $52.4(3.0)^{*}$ & $85.4(3.5)^{* * *}$ & $106.5(4.4)^{* * * *}$ \\
\hline $\mathbf{N}_{\text {OB }}$ & 2 & $45.8(2.6)$ & $71.8(2.6)^{\#}$ & $89.2(3.2)^{\#}$ \\
\hline
\end{tabular}

